\title{
Peter Por, Voies hyperboliques. Figures de la création poétique des Lumières à la modernité
}

\section{Luigi Luison}

\section{Q OpenEdition}

1 Journals

\section{Edizione digitale}

URL: https://journals.openedition.org/studifrancesi/40093

DOI: 10.4000/studifrancesi.40093

ISSN: 2421-5856

\section{Editore}

Rosenberg \& Sellier

\section{Edizione cartacea}

Data di pubblicazione: 1 décembre 2004

Paginazione: 437-438

ISSN: 0039-2944

\section{Notizia bibliografica digitale}

Luigi Luison, «Peter Por, Voies hyperboliques. Figures de la création poétique des Lumières à la modernité», Studi Francesi [Online], 143 (XLVIII | II) | 2004, online dal 30 novembre 2015, consultato il 19 mai 2021. URL: http://journals.openedition.org/studifrancesi/40093; DOI: https://doi.org/10.4000/studifrancesi. 40093

Questo documento è stato generato automaticamente il 19 mai 2021.

\section{(c) (1)}

Studi Francesi è distribuita con Licenza Creative Commons Attribuzione - Non commerciale - Non opere derivate 4.0 Internazionale. 


\title{
Peter Por, Voies hyperboliques. Figures de la création poétique des Lumières à la modernité
}

\author{
Luigi Luison
}

\section{NOTIZIA}

PETER POR, Voies hyperboliques. Figures de la création poétique des Lumières à la modernité, Paris, Editions Champions, 2003, pp. 386.

1 L'A. colloca questa raccolta nello spazio che intercorre tra due tesi che ritiene fondamentali, nonché in contraddizione. L'una predica che l'opera letteraria contiene ed impone le categorie del proprio significato, mentre l'altra predica la mancanza di un significato definitivo, e che le categorie dell'esegesi dell'opera non possono che evocarne continuamente di nuove. Appare evidente e di facile riconoscimento che in queste due tesi sono insite le due tendenze della riflessione critica che hanno contrassegnato lo strutturalismo.

2 Il volume è suddiviso in tre sezioni, ognuna delle quali mette a confronto autori del periodo classico e romantico francese e tedesco, con una dettagliata analisi di alcuni passaggi estratti dalle opere più significative.

3 Con questo testo l'A. si propone di evitare l'opposizione tra i due concetti della creazione e del segno, dell'unità e delle giunture, e di tentare di considerarli come concetti correlativi, che si descrivono e si determinano scambievolmente. Èda questo rapporto che si è sviluppata la tendenza per eccellenza, cioè la «modernità classica».

Lo studio effettuato dall'A integra alcune analisi di opere e fenomeni che contrassegnano i confini di questa tendenza. In effetti, le pagine dedicate all'opera di Schiller hanno come scopo quello di attenuare l'immagine di un classico lontano e di mettere in risalto colui che ha creato l'opera, instaurando il carattere antinomico dell'epoca successiva. 
5 Nei capitoli centrali l'A. presenta scrittori come Baudelaire, Apollinaire, Rilke ed Hoffmansthal e cerca di abbozzare una definizione generale di ciò che viene chiamato «style 1900». Questo percorso porta poi l'A a collegarsi al romanticismo tedesco per dimostrare in quale modo i poeti della «modernità classica» hanno modificato il valore della personalità e dell'espressione dell'Io poetico.

Il volume, come spiega l'A., è stato redatto contemporaneamente all'edizione in lingua ungherese e per due terzi entrambe le edizioni risultano identiche, ma, mentre al volume in lingua ungherese l'A. ha preferito attribuire il titolo di Inscription de ton existence, per quanto riguarda l'edizione in lingua francese l'A ha ritenuto opportuno evidenziare «l'intérêt existentiel de tous les systèmes de signes artistiques». Di conseguenza il lavoro che si rivolge ai lettori di lingua francese racchiude una doppia accezione: l'iperbole vista sia come figura stilistica che come figura geometrica. Questa immagine, infatti, rappresenterebbe le due vie della creazione post-moderna che disegnano un rapporto iperbolico da una all'altra, un rapporto di similitudine e di scarto, che si apre verso l'infinito oppure sul nulla. La bibliografia è ampia, soprattutto per quanto riguarda i testi in lingua tedesca. 